\title{
$\begin{array}{ll}\text { Research Square } & \text { Preprints are preliminary reports that have not undergone peer review. } \\ \text { They should not be considered conclusive, used to inform clinical practice, }\end{array}$
}

\section{Utilization of Maternity Waiting Homes to Increase Uptake of Immediate Postpartum Family Planning in Primary Health Care Facilities in Ethiopia}

\section{Mengistu Asnake}

Pathfinder International

Bekele Belayihun Tefera ( $\sim$ bbelayihun@pathfinder.org )

Pathfinder International https://orcid.org/0000-0002-0967-623X

Yeowndwossen Tilahun

Pathfinder International

\section{Habtamu Zerihun}

Pathfinder International

\section{Fisseha Moges}

Pathfinder International

\section{Adeba Tasissa}

Pathfinder International

\section{Zerihun Tilahun}

Pathfinder International

Atsede Taddelle

Pathfinder International

Wondimagegnehu Workneh

Pathfinder International

\section{Research}

Keywords: Contribution, Ethiopia, Family Planning, Immediate Postpartum, Maternity Waiting Home, Health Facilities

Posted Date: June 19th, 2020

DOI: https://doi.org/10.21203/rs.3.rs-35951/v1

License: (c) (i) This work is licensed under a Creative Commons Attribution 4.0 International License. Read Full License 


\section{Abstract}

Background: Maternity waiting home (MWH) within primary health care facilities is an ideal platform to reach women with family planning education and counseling. MWH users interact with health care providers on a regular basis throughout their waiting period and can prepare to initiate family planning method of their choice immediately after childbirth. However, to date, there has been no clear evidence about the use of MWHs to increase uptakes of immediate postpartum family planning (IPPFP). Therefore, the aim of this study is to assess the contribution of MWHs to increase IPPFP uptake among women who deliver in health facilities in Ethiopia.

Methods: A comparative cross-sectional study design was conducted to collect quantitative data from women who gave birth in the past 12 months. Multi-stage random sampling procedures were employed to select 884 women. Descriptive summary and logistic regression with 95\% confidence intervals were conducted in Stata 14 to analyze the data.

Result: The prevalence of IPPFP use among women who used MWHs was $44 \%$ and $36 \%$ among those who did not use $\mathrm{MWHs}$. The use of MWHs significantly contributed to increase immediate postpartum family planning uptake $(\mathrm{OR}=$ $1.48,95 \% \mathrm{Cl}=1.08-2.04, \mathrm{p}=.016)$.

Conclusions: This study showed that, MWHs significantly contributed for improving IPPFP uptake by an average of $8 \%-$ point difference for beneficiaries within 48 hours after delivery. Developing a comprehensive package of service for maternal care has the potential to improve family planning uptake of postpartum women.

Women's who have used maternity waiting home more likely utilized postpartum family planning than women who have not used maternity waiting home. Providing a comprehensive package of services, including family planning information and counseling, in maternity waiting homes can have a positive impact on improving postpartum family planning use.

\section{Plain English Summary}

Maternity waiting home is an ideal platform to reach women with family planning education and counseling because clients interact with providers throughout their waiting time. In this study investigate the uptake of postpartum family planning among women in the maternity waiting home and walking women to deliver in the facility using client survey data. Respondents were asked about the maternity waiting home utilization and their received services during their visit. Of the 884 respondents, 361 women used maternity waiting home and 523 women not used maternity waiting home were participated in this study. From the total participant, 274 women received postpartum counseling during their waiting time. Maternity waiting home contributed to improve postpartum family planning uptake.

\section{Background}

Ethiopia is one of the Sub-Saharan Africa countries which has achieved a rapid increase in its modern contraceptive prevalence rate (CPR) - increasing from 14\% in 2005 to 41\% in 2019 [1]. Despite the rapid increase in contraceptive prevalence, the unmet need for postpartum family planning (PPFP) still remains high[1-4]. Most postpartum women want to delay or avoid future pregnancies, but not use modern contraceptive methods - a situation referred to as "unmet need" for family planning (FP) [5,6]. Previous evidence shows that there is a high level of unmet need for contraception among postpartum women in the Sub-Saharan Africa region [ 4, 7]. The postpartum period is a critical time to address unmet FP needs and to reduce the risks related to closely spaced pregnancies [8-10]. Different studies show that some women have become pregnant early in the postpartum period [11, 12], given that there is a resumption of sexual activity, leads to women seeking FP method [13]. Postpartum family planning information helps a woman to decide whether to 
use contraception, and if they do, what contraceptive they want to use. Additionally, it helps women decide to continue to use for two years or longer after giving birth, depending on the reproductive needs of the woman [14].

In developing countries, most people live in rural areas, where poor access to maternity services accounts for many maternal and perinatal deaths [15]. One of the strategies to tackle maternal and neonatal child health challenges related to distance linked to geographical access is establishing maternity waiting homes (MWHs). MWHs are residential places within the health facilities close to the delivery unit (health centers or hospitals) for pregnant women from rural areas to overcome the barriers of distance and time to reach to the health center [16]. In addition to various services the MWHs provides to the pregnant women and the fetal wellbeing, they also share health education on FP, newborn care, breast-feeding, and multiple other health services [17]. According to WHO recommendation, women should receive information on family planning and the health and social benefits of birth spacing during ANC, immediately after birth, and during postpartum. Women should also receive information on well-baby care, including immunization and growth monitoring [18]. Healthcare providers should be encouraged to provide counseling on postpartum family planning through the continuum of pregnancy [19]. Each visit to a health professional offers a unique opportunity to counsel and offer FP services. The MWH is an ideal platform to reach women with FP education and counseling and respond to the needs of those women having access because of distance and other geographic barriers [20]. MWH users interact with health care providers on a regular basis throughout their waiting period and can prepare to initiate an FP method immediately after childbirth. However, providers may neglect this window of opportunity to improve immediate postpartum family planning (IPPFP) among clients using MWHs in Ethiopian public health centers.

Studies show that $12 \%$ of women who have delivered in a facility received postpartum family planning for the extended period until 12 months after delivery in eastern Ethiopia [11]. 22\% of women received immediate postpartum- Introduce intrauterine devices (IUDs) in southern Ethiopia [20] and more than $45 \%$ of postpartum women received long-acting and reversible contraceptives (LARCs) in western and central parts of the country $[21,22]$. Within the national average of postpartum uptake, $8 \%$ of postpartum women received FP during the first month of child birth and $21 \%$ of women received FP at six months. $26 \%$ of women during the first year of the postpartum period indicated IPPFP provision remains a challenge in Ethiopia [23].

A United States Agency for International Development (USAID) funded project, Transform: Primary Health Care, began supporting the Ethiopian government to implement an IPPFP initiative in primary health care facilities across four regions of the country since 2017 [24]. IPPFP services availability, within 10 minutes to 48 hours of child birth, was limited in delivery rooms in Ethiopia until the MWH scale-up by the government in 2017. Therefore, there is no clear evidence about the contribution of MWHs to increase IPPFP use among women who delivered in primary health care facilities after implementing IPPFP initiative. However, such information would be necessary to establish evidence on IPPFP integration within MWHs to be truly responsive to the needs of clients [18]. The main aim of this study is to answer the following question: What was the relative contribution of MWHs to increase IPPFP uptake?

\section{Methods}

\section{Study Area and Period}

In 2017, USAID Transform: Primary Health Care project primarily implemented by Pathfinder International, John Snow Inc. and other partners, began supporting the government's IPPFP initiative in 1225 primary health care facilities. The project is being implemented in four regions - including Amhara, Oromia, the Southern Nations, Nationalities, and People's (SNNP), and Tigray - in collaboration with each Regional Health Bureau. The project catchment area covers 406 districts (woredas) and approximately $50 \%$ of the Ethiopian population across these four regions. The study was conducted in selected health centers located within USAID Transform: Primary Health Care's implementation regions

Page $3 / 16$ 
and focuses on women who delivered in the past 12 months prior to the study. Data was collected from October through December 2019.

\section{Study Design and Sampling}

The study employed a comparative cross-sectional study design with a quantitative approach to assess IPPFP utilization among women who delivered in the health centers. The study categorized the women into two categories including those who used MWHs and those who did not use MWHs (walk-in deliveries). The study was conducted in the health centers with MWHs providing delivery and IPPFP services in the project intervention regions. The sampling frame was all health centers which have MWH facilities and provide deliveries and IPPFP services under the project catchment areas. $143 \mathrm{HCs}$ are listed under the project areas, but only $44 \mathrm{HCs}$ have a functional $\mathrm{MWH}$ and provide skilled delivery and IPPFP services. 15 of these HCs were randomly selected for this study. Four health centers from each region were selected from Amhara, Oromia, and SNNP, and three health centers were selected from Tigray.

The second sampling frame list includes all women (name and their address) who delivered in the selected health centers (both who used and who did not used MWHs) for the past one year from the delivery registration book. 9275 women had delivered in the past 12 months in the selected facilities (on average 618 women delivered per HCs). Of which, $40 \%$ (3710) of women had used MWHs and delivered in the facilities (247 women per HC). The study randomly selected 62 women from each health center (10\% of the total delivery), including a proportion of $40 \%$ of women who used MWHs ( 25 women) and $60 \%$ of women who did not use MWHs (37 women). In total, this provided 930 women who delivered in the selected health centers $(62 * 15 \mathrm{HCs})$, where 375 women used MWHs and 555 women did not. Women who have an experience of stillbirth or newborn death in their last delivery were excluded from the study to avoid respondent bias.

After identifying the study participants (postpartum women), the women were traced from the community through health extension workers (HEWs) who informed them about the purpose of the study. All women willing to participate in the study were invited to participate in an interview at a proposed time and place through the HEWs. The data collectors conducted the interviews with the support of HEWs. Of those eligible but who did not respond: 17 (1.8\%) were unavailable during their scheduled time and place, 13(1.4\%) refused participation, $9(1 \%)$ withdrew after beginning the interview or had incomplete surveys, and $7(0.8 \%)$ women had a stillbirth and were wrongly recorded in the delivery record and were dropped from the analysis. The final data was analyzed with a final sample of 884 participants (361 women who used $\mathrm{MWH}, 523$ women who not use $\mathrm{MWH}$ ) at a $95.1 \%$ response rate.

\section{Data Collection Process}

The data was collected using a structured questionnaire developed based on existing literature, previous experience on questionnaire preparation on Postpartum intrauterine contraceptive devices (PPIUCD) research [25, 26], and through discussion with subject area experts. The questionnaire consists of three sub-sections designed to assess: 1) sociodemographic characteristics of women; 2) women's experience on health education and counseling on IPPFP during their stay in the MWHs; and 3) practice of health service utilization during pregnancy and birth (e.g., delivery complication, mode of delivery) and utilization of IPPFP. In addition to the structured questionnaire, the MWH service standard checklist was used to record all services provided in the MWH [27]. The questionnaire was translated into local languages (Amharic, Tigrigna, and Afan Oromo) prior to the start of the fieldwork. All interviews were conducted in local languages. 20 data collectors and four supervisors, who were fluent in the local languages and experienced in family planning/reproductive health-related data collection, conducted the data collection process. A three-day training was

provided to data collectors and supervisors on the content of the questionnaire, issues of confidentiality, ethical conduct of human subject research, and data collection techniques. The training included pretesting the questionnaire in 
adjacent health centers that were not included in the study. Pre-testing of the data collection instrument was aimed at assessing: (1) how well the instruments elicit the information needed (2) the usefulness of the information collected and (3) the competency of the data collectors. Based on the pre-test results, the instrument was modified. After providing data collection training and modifying the final questionnaire, two data collectors and one supervisor were assigned to each of the regions.

\section{Data Processing and Analysis}

The research team assessed the quality, accuracy, and completeness of the collected data using range plausibility and cross-validation checks. Data was checked, coded, and entered using Epi-Data version 3.2. The accuracy of data entry was checked by running frequency analysis and making range checks every time data was entered. The data entry errors were corrected by cross-checking with the completed questionnaire. After completing the data entry, the data was exported to SPSS version 20 for further analysis. Descriptive statistics and logistic regression were used to analyze the data. Bivariate analyses were done to select important variables for the multivariable analysis. Variables with $p$-value $\leq 0.25$ in bivariate analyses were transferred into a multivariable logistic regression to manage confounding effects. And an adjusted odds ratio with $95 \%$ level of significance was considered for those variables which were found to have significant association ( $p$-value $\leq 0.05$ ) with the outcome variable (IPPFP use). All variables that were considered in the analysis are described in Table 1.

\section{Results}

\section{Socio-Demographic Characteristics}

The average age of the respondents was 28 years ( $m e a n=27.7$, standard deviations $(S D s)= \pm 5.6$ ), and approximately $46 \%$ of the respondents were in the $25-30$-year-old age bracket. Most of the respondents (81\%) were rural residents and $92 \%$ of the MWHs users were rural residents. Of all the respondents, $53 \%$ had some level of education (able to read and write), of which $69 \%$ had completed primary education. Of all the respondents/ women, $56 \%$ of them used MWHs. Most of the respondents were currently married ( $81 \%$ ) and $15.6 \%$ were living with their sexual partners but were not currently married (Table 2).

\section{Reproductive Histories of Respondents}

At the time of the study, the average number of live children was 3 (mean $3 \pm 1.7 S D$ ). Half of the respondents (53\%) reported that they had 36 or more months of spacing and $14 \%$ of women reported less than 24 months between their current and last birth. Of which $55 \%$ and $13 \%$ of them used MWHs, respectively. Almost $90 \%$ of the respondents had delivered through normal delivery, followed by $8 \%$ of women who delivered through vacuum -assisted delivery. Overall, $68 \%$ of the study participants attended four or more antenatal care (ANC) visits and $30 \%$ attended ANC between two and three times. Of which $66 \%$ of postpartum women who attended four or more ANC visits had used MWHs. Approximately $84 \%$ of respondents indicated that they have used some form of contraception before their most recent birth. $56 \%$ and $36 \%$ of women had used injectable contraceptives and implants, respectively. Most of the respondents $(87 \%)$ reported that their children from their last delivery were immunized. Of these women, $87 \%$ of them had used MWHs. $72 \%$ of the respondents had their last birth in health facilities (Table 3).

\section{Contribution of Maternity Waiting Homes}

From the total respondents, $41 \%$ of women had used MWHs before delivery. Of which, 55\% stayed for five or less days and $15 \%$ stayed more than 15 days. From the total women who used MWHs, $76 \%$ received IPPFP counseling. Off the women who used MWHs and received IPPFP counseling, more than half (54\%) adopted IPPFP. There was a significant 
difference (6\% points) between women who used MWHs and did not used MWHs, but both received IPPFP counseling on IPPFP utilization ( $p=0.008$ ). The overall prevalence of IPPFP use was $39.4 \%$. Of those who immediately received postpartum family planning, $36 \%$ received services within 10 minutes and $64 \%$ received within 48 hours of delivery (Data not shown).

The prevalence of IPPFP use among women who used MWHs was $44 \%$ and $36 \%$ among those who did not use MWHs. There was a significant difference ( $8 \%$ points) between women who used MWHs and did not use MWHs in IPPFP utilization $(p=0.007)$. Of those women who used $\mathrm{MWH}$ s and received immediately postpartum family planning, $41 \%$ received services within 10 minutes and $59 \%$ received within 48 hours of delivery. There was a significant difference (11\% points) between women who used MWHs and did not use MWHs in time to receive IPPFP service $(p=0.036)(T a b l e$ 4).

Among both categories of women, the most commonly used FP methods were Implanon followed by IUCD. The use of Jadelle among women who used MWHs was very low compared to those who did not use MWHs $(p=0.009)$. However, the proportion of women who used MWHs and adopted the IUCD was higher than among women who did not use MWHs ( $p=0.011)$. The major reasons for postpartum women not using IPPFP included: a desire to have another child/pregnancy soon, and not receiving IPPFP counseling. These were the major reasons among those women who used and did not use MWHs (Table 4).

\section{Factors Associated with Immediate Postpartum Family Planning Use}

Of the selected 11 variables, ten of the predictors were related with immediate postpartum family panning use $(p \leq 0.25)$ in bivariate analysis. Based on the findings, all variables $(p \leq 0.25)$ in bivariate analysis were included in a multivariable logistic regression model. Predictors of IPPFP use included marital status, immediate PPFP information and counseling, the use of MWHs. Women who visited the health facility for child immunization had a significant association $(p \leq 0.05)$ on immediate PPFP use in multivariable logistic regression. Postpartum women who had received IPPFP counseling were five times more likely to utilize IPPFP within 10 minutes to 48 hours postpartum (AOR=5.26; 95\% $\mathrm{Cl}$ : 3.12-8.87, $\mathrm{p}=0.000)$ as compared women who had not received IPPFP counseling. Women who used MWHs before delivery were 1.5 time more likely to utilized IPPFP than women who did not used MWHs (AOR=1.48; 95\% CI: 1.1-2.0). Postpartum women who had information about IPPFP from any source were more likely to utilize IPPFP than those women who had no information (AOR=1.97, 95\% Cl: 1.3-3.0) (Table 5).

\section{Discussion}

Results indicated a positive association between MWHs use and uptake of IPPFP. The study findings suggested that postpartum women who were counseled before or during delivery were more likely to utilize contraceptive methods in their immediate postpartum period than others. This finding is supported by other evidence which shows a positive relation between IPPFP use and FP counseling before or during delivery [28]. Studies have shown MWHs remain an important window of opportunity to provide access to FP messages and to offer women with various options of contraceptive methods $[29,30]$. Therefore, the study finding informs the need for service integration within the different service units in the public health facilities to take advantage of the MWHs to increase IPPFP uptake. In this study, the use of MWHs was associated with an increased uptake of IPPFP (AOR=1.48 and 95\% $\mathrm{Cl}(1.08-2.04)$ ). The prevalence of IPPFP use among women who used MWHs was $44 \%$ and $36 \%$ among those who did not use MWHs. There was $8 \%-$ point difference in IPPFP uptake between postpartum women who used and did not use MWHs $(p=0.007)$.

Postpartum women who had information and received counseling about IPPFP were more likely utilize IPPFP than others. Postpartum women who delivered in public health facilities and used or not use MWHs have an equal 
opportunity to be exposed to FP information and IPPFP counseling during delivery. The use of MWH services is a valuable opportunity to increase contact of healthcare providers with pregnant women and create possibilities for peer to peer discussion among pregnant women to provide and discuss about IPPFP. However, $76 \%$ of postpartum women who used MWHs have an additional opportunity to exposed IPPFP information and additional counseling. More than half (54\%) of postpartum women who used MWHs and received IPPFP counseling, adopted IPPFP. Therefore, postpartum women who had used MWHs before delivery were about more likely exposed family planning information $(A O R=1.97 ; 95 \% \mathrm{Cl}(1.28-3.03))$ and received counselling (AOR=5.26; 95\% $\mathrm{Cl}(3.12-8.87)$ ) than other women. This study was supported by studies conducted in Ethiopia and Uganda, which stated that women who had exposure on family planning information were significantly more likely to use postpartum family planning $[11,33]$. Previous evidence has also reported an association between contraceptive use and MWHs in Kenya and Ethiopia [31,32]. The findings of this study suggest that the expansion of MWHs has the potential to further increase use of contraceptive services during the immediate postpartum period. Developing a comprehensive package of services for maternity care facilities has a great role to play in improving the availability, accessibility, and acceptability of IPPFP use in resource limited settings [25].

The study result showed a positive association between educational status and uptake of IPPFP. Postpartum women whose educational status was secondary or above were more likely to utilize IPPFP compared to those who are illiterate. This might be due to the attainment of educational level exposing women to a better understanding of PPFP information and counseling during the postpartum period. Similar studies support this finding that postpartum women with a secondary education have an increased awareness of PPFP and are more likely to utilize the expedited method of IPPFP $[11,34,35]$.

The use of modern contraceptive methods is low in low-income countries, but most women seek immunization services for their children. In 2019, immunization coverage reached $72 \%$ in Ethiopia (as measured by the estimated delivery of DTP3) [36]. Through child immunization visits, postpartum women have multiple contacts with health care providers, providing an added opportunity for women to be exposed to PPFP counseling. In this study, $86 \%$ of postpartum women (both who used and not used $\mathrm{MWH}$ ) have had child immunization experience. Of the postpartum women who used MWHs and had child immunization experience, 78\% received IPPFP counseling. Out of these women, 55\% adopted IPPFP. A previous study found that FP messages integrated during immunization visits was associated with a $54 \%$ increase in the average new FP acceptors [37]. Other literature also suggests that among 12 to $15 \%$ of women who actively sought child immunization also received a long-acting method during their visit [38].

The study finding confirmed that, there is a significant difference in IPPFP uptake in both women who have had used and don't used MWHs. Even through, the rate for women not used MWHs is higher compared to the national figures of IPPFP use [23]. This is basically related to the project contribution in improving IPPFP services across the project area; because the project supports the immediate PPFP program through the following activities: i) Improving the FP/RH service delivery system through implementation of different service delivery approaches; and ii) integrating FP services within the health system across the continuum of pregnancy, and birth. The project provided capacity enhancement in IPPFP training for health care providers working in the delivery room, service provisions were initiated and utilization of IPPFP increased [39].

\section{Limitations}

This study is limited by its focus on USAID Transform: Primary Health Care implementation woredas/districts, which constrains generalization beyond the project districts selected for this study. The 15 health centers in the study are part of the project intervention facilities and have had considerable resources provided over the past three years and it's likely that outcomes in these health centers are better than non-project health centers. Finally, several questions relied on participant's recall of events over the past 12 months, potentially creating recall bias by participant's ability to 
accurately recall. Also, there is a possibility of social desirability bias as women may have wanted to report "good behavior".

\section{Conclusions And Recommendation}

This study examined the relationship between the use of MWHs and the uptake of FP services during the immediate postpartum period. Providing a comprehensive package of services, including FP information and counseling, in MWHs can have a positive impact on improving IPPFP use. By designing and implementing a holistic approach to maternal and child health care in the health facilities, MWHs create the opportunity to increase contact of healthcare providers with pregnant women, high possibilities for peer to peer discussion among pregnant women and ultimately improve immediate postpartum family planning use. Future research is needed on the cost implications of integrating IPPFP in MWHs in the healthcare facilities and looking at the situation of IPPFP in non-project areas.

\section{Declarations}

\section{Ethical Consideration:}

Permission to carry out the study was obtained from the Amhara, Oromia, SNNP, and Tigray Regional Health Bureau IRB committee and permission was secured from the District/Woreda Health Offices. Each respondent gave informed verbal/oral consent after being told the purpose and procedures of the study. All respondent identification was kept confidential and anonymous.

\section{Consent for Publication:}

Note applicable.

\section{Competing Interests:}

The authors declare they have no competing interests.

\section{Availability of Data and Materials:}

The datasets used in this study are not publicly available to ensure individual privacy. All information related to the processed data is underlying the results section. The raw data used in this analysis is available from the corresponding author on reasonable request.

\section{Funding:}

This paper was developed with the generous support of USAID under the cooperative agreement of AID-663-A-17-00002. All opinions expressed herein are of the authors and don't necessarily reflect the views of Pathfinder International or USAID. The funding organization has no any role in developing this article.

\section{Authors' Contribution:}

MA, BT, YT, HZ, AT, AT, WW, ZT and FM participated in the planning and coordination of this study including data collection and write up, designing, and drafting of the manuscript. MA and BT revised and approved the final manuscript.

\section{Acknowledgment:}


The authors are very grateful to Talia F, Yordanos $\mathrm{M}$, and Chidude $\mathrm{O}$. for their critical review and valuable inputs during the abstract submission and for further developing this manuscript. Furthermore, the authors would like to appreciate the contribution of data collectors and regional monitoring and evaluation officers, and FP/SRH program officers.

\section{Abbreviations}

Antenatal Care (ANC); Contraceptive Prevalence Rate (CPR); Family Planning (FP); Health Center (HC); Health Extension Workers (HEWs); Immediate Postpartum Family Planning (IPPFP); intrauterine contraceptive devices (IUDs); LongActing and Reversible Contraceptives (LARCs); Postpartum Family Planning (PPFP); Postpartum intrauterine contraceptive devices (PP-IUDs); Maternity Waiting Home (MWH); Southern Nations, Nationalities, and People's (SNNP); United States Agency for International Development (USAID).

\section{References}

1. Central Statistical Agency [Ethiopia]. Ethiopia Mini Demographic and Health Survey 2019. Addis Ababa(Ethiopia): ICF International Calverton, Maryland, USA; 2019 Mar p. 452; Available: http://www.unicef. org/ethiopia/Mini_DHS_2019_Final_Report.pdf

2. Central Statistical Agency [Ethiopia]. Ethiopia Demographic and Health Survey 2011. Addis Ababa(Ethiopia): ICF International Calverton, Maryland, USA; 2011 Mar p. 452; Available from: http://www.unicef.

Org/ethiopia/DHS_2011_Final_Report.pdf

3. Central Statistical Agency [Ethiopia]. Ethiopia Demographic and Health Survey 2016. Addis Ababa(Ethiopia): ICF Rockville, Maryland, USA; 2016 Jul p. 549; Available from: http://www.unicef.

org/ethiopia/DHS_2016_Final_Report.pdf

4. Moore Z, Pfitzer A, Gubin R, Charurat E, Elliott L, Croft T. Missed opportunities for family planning: an analysis of pregnancy risk and contraceptive method use among postpartum women in 21 low- and middle-income countries. Contraception,2015; 92(1):31-9.

5. FHI360. Integration of Postpartum Family Planning with Child Immunization Services: A Promising Approach to Improving Maternal and Child Health. FHI360/RWANDA;2013.

6. Borda MR, Winfrey W, McKaig C. Return to sexual activity and modern family planning use in the extended postpartum period: an analysis of findings from 17 countries. Afr J Reprod Health, 2010;14(4):72-9.

7. John A., William L. Contraceptive Use, Intention to Use and Unmet Need During the Extended Postpartum Period. Int Fam Plan Perspect; 2001;27(1):20-7.

8. Pathfinder International. Expanding Contraceptive Options for postpartum women in Ethiopia: Introducing the postpartum IUCD. 2016. https://www.pathfinder.org/publications/expanding-contraceptive-options-for-postpartumwomen-in-ethiopia. Access February 20,2020.

9. Borda M, Winfrey W. Postpartum Fertility and Contraception: an analysis of findings from 17 countries.

Futures/constella for ACCESS-FP 2010, Jhpiego: Baltimore, Maryland; pp: 11-50.

10. Central Statistical Agency. Ethiopia Mini Demographic and Health Survey 2014. Addis Ababa (Ethiopia): ICF Rockville, Maryland, USA; 2014; Available: http://www.unicef. org/ethiopia/Mini_DHS_2014_Final_Report.pdf

11. Nigussie A, Girma D, Tura G. Postpartum Family Planning Utilization and Associated Factors among Women who Gave Birth in the Past 12 Months, Kebribeyah Town, Somali Region, Eastern Ethiopia. J Womens Health Care, 2016; $5: 340$.

12. Tesfay F, Oesfin E. Assessment of Sexual Activity in Postpartum in union Women in Addis Ababa, Ethiopia: A prospective cross-sectional descriptive study in six immunization clinics. 2014. 
http://etd.aau.edu.et/bitstream/handle/123456789/1064/Frewoini\%20Tesfay.pdf. ACCESS May 3,2020

13. Alum AC, Kizza IB, Osingada CP, Katende G, Kaye DK. Factors Associated with Early Resumption of Sexual Intercourse among Postnatal Women in Uganda. Reprod Health,2015; 12:1-8.

14. World Health Organization. Programming Strategies for Postpartum Family Planning. WHO, Department of Reproductive Health and Research; 2013

15. World Health Organization. WHO -Recommendation on Establishment of Maternity Waiting Homes (MWHs)? Geneva: WHO; 2015. [Google Scholar].

16. World Health Forum. A maternity waiting home reduces obstetric catastrophes· PubMed;1990

17. World Health Organization. Maternity Waiting Homes: A review of experiences. Geneva: World Health Organization, Maternal and Newborn Health Safe Motherhood Unit. Division of Reproductive Health; 1996.

18. MCSP. Leveraging Antenatal Care to Increase Uptake of Postpartum Family Planning: A Key Time for Counseling; January 2018. https://www.mcsprogram.org/resource/leveraging-antenatal-care-increase-uptake-postpartumfamily-planning-key-time-counseling/. ACCESS APRIL 12020.

19. Penn-Kekana L, Shreya P, Julia H, Hannah B, Matthew C, Stephen M and, et al. Understanding the Implementation of Maternity Waiting Homes in Low- and Middle-Income Countries: a Qualitative Thematic Synthesis. BMC Pregnancy Childbirth, 2017;17:269.

20. Lidetu BT, Mulumebet A, Chaltu F, Dawit JT. Utilization of Immediate Post-Partum Intra Uterine Contraceptive Device and Associated Factors: A Facility Based Cross Sectional Study among Mothers Delivered at Public Health Facilities of Sidama Zone, South Ethiopia. J Pregnancy Child Health, 2017;4:326.

21. Arero, W, Teka, W, Jarso, Habtamu H. Prevalence, and Pattern of LARC Use in Immediate Postpartum Period at Jimma University Medical Center, Ethiopia. Obstet Gynecol, 2018;131:68S.

22. Lemi B, Malede B. Factor Affecting Long-Acting Terms and Permanent Contraceptive Uptake among Immediate Post-Partum Mothers At saint Paul's Hospital Millennium Medical College, Addis Ababa, Ethiopia. Ethiop J Reprod Health, 2018; 10(2):31-41.

23. Track20. Opportunities for Family Planning Programming in the Postpartum Period in Ethiopia. http://www.track20.org/download/pdf/2017\%20PPFP\%200pportunity\%20Briefs/english.ACCESSED 3 FEB 2020.

24. USAID Transform: primary health care project document, 2017, Addis Ababa, Ethiopia (4)

25. Lori, J.R., Perosky, J., Munro-Kramer, M.L. et al. Maternity Waiting Homes as part of a Comprehensive Approach to Maternal and Newborn Care: a cross-sectional survey. BMC Pregnancy Childbirth,2019; 19:228.

26. Tilahun Y, Mehta S, Zerihun H, Lew C, Brooks MI, Nigatu T, et al. Expanding access to the intrauterine device in public health facilities in Ethiopia: a mixed-methods study. Glob Health Sci Pract, 2016;4(1):16-28.

27. Ministry of Health [Ethiopia]. Service Standards of Maternity Waiting Homes at the Health center level, Addis Ababa, Ethiopia. Ministry Heath of Ethiopian; 2012.

28. WHO, UNICEF, UNFPA, World Bank, UNPD. Trends in Maternal Mortality 1990 to 2015. WHO; 2015.

29. Regassa N. Antenatal and Postnatal Care Service Utilization in Southern Ethiopia: a Population-Based Study. African Health Sciences,2011;11:3.

30. Jacobs C, Michelo C, Chola M, Oliphant N, Halwiindi H, Maswenyeho S, et al. Evaluation of a Community-Based Intervention to Improve Maternal and Neonatal Health Service Coverage in the Most Rural and Remote Districts of Zambia. PLoS One, 2018;13(1):e0190145.

31. Joyce M, Kazuyo M, Michael M, Carol M, Caroline K, John C. Contraceptive Use and Discontinuation Among Postpartum Women in Nairobi urban slums. Presentation on IUSSP Seminar on Promoting Postpartum and Post- 
Abortion Family Planning, Cochin, India. 2014; https://www.popcouncil.org/uploads/pdfs/2014STEPUP_IUSSPIndiaMumah.pdf. ACCESS APRIL 102020

32. Do M, Hotchkiss D. Relationships between Antenatal and Postnatal Care and Postpartum Modern Contraceptive Use: Evidence from Population Surveys in Kenya and Zambia. BMC Health Serv Res, 2013;13(1):6.

33. Rutaremwa G. Contraceptive Use During the Postpartum Period among Women in Uganda: BMC Public Health,2015: 262.

34. Intra health. Pre-service Education Family Planning reference guide. 2010; https://www.intrahealth.org/resources/preservice-education-family-planning-reference-guide

35. Sundaram A. Benefits of Meeting the Contraceptive Needs of Ethiopian Women. New York: Guttmacher Institute.2014.

36. WHO, UNICEF. Ethiopian Estimates of National Immunization Coverage, July 2, 2019; pag26 http://www.who.int/immunization/monitoring_surveillance/routine/coverage/en/index4.html

37. Huntington D, Aplogan A. The Integration of Family Planning and Childhood Immunization Services in Togo. Stud Fam Plann, 1994;25(3):176-83

38. Population Services International. Reaching Women in Need of Family Planning at Clinic Immunization Days. http://www.psi.org/sites/default/files/publicationfiles/Mali\%20Case\%20Study\%20LETTER\%20SIZE\%20PAGES.pdf

39. USAID Transform: Primary Health Care Project year 3 annual report, 2019, Addis Ababa, Ethiopia

\section{Tables}




\begin{tabular}{|c|c|}
\hline Variable & Definitions \\
\hline $\begin{array}{l}\text { Dependent } \\
\text { variable: } \\
\text { Immediate } \\
\text { post-partum } \\
\text { family } \\
\text { planning use }\end{array}$ & $\begin{array}{l}\text { PPFP methods provided during the immediate or early postpartum period, meaning, within } 10 \\
\text { minutes or up to } 48 \text { hours after birth [29]. Women who utilized any FP method within } 10 \text { to } 48 \\
\text { hours after birth. } 1=\text { yes, } 0=\text { otherwise }\end{array}$ \\
\hline \multirow{3}{*}{$\begin{array}{l}\text { Predictor } \\
\text { variables: } \\
\\
\text { Maternity } \\
\text { Waiting } \\
\text { Home }\end{array}$} & $\begin{array}{l}\text { MWH refers to a waiting area/house prepared in a health center compound for pregnant women } \\
\text { identified to be at risk who receives services, including health services, and later to delivers with a } \\
\text { skilled provider in a facility [30]. Women who stayed in } \mathrm{MWH}=1,0=\text { otherwise }\end{array}$ \\
\hline & \\
\hline & Age of the women in years \\
\hline Age & Current residence of the women. $1=$ urban, $0=$ rural \\
\hline Resident & Level of education. $1=$ cannot read/write (illiterate), $2=$ primary, and 3=secondary and above \\
\hline $\begin{array}{l}\text { Marital } \\
\text { Status }\end{array}$ & Marital status of the women. $1=$ married, $0=$ otherwise \\
\hline $\begin{array}{l}\text { Number of } \\
\text { live children }\end{array}$ & The women who gave birth and the number of alive children \\
\hline Ever Used FP & Women who have an experience of FP use. $1=y e s, 0=$ otherwise \\
\hline ANC & Women who have received ANC services and the number of ANC visits in the facility \\
\hline $\begin{array}{l}\text { Child } \\
\text { Immunization } \\
\text { exp }\end{array}$ & Women who have their last child immunized. $1=y e s, 0=$ otherwise \\
\hline $\begin{array}{l}\text { IPPFP } \\
\text { information }\end{array}$ & Women who received information about immediate PPFP from any source. $1=y e s, 0=$ otherwise \\
\hline $\begin{array}{l}\text { IPPFP } \\
\text { counseling }\end{array}$ & $\begin{array}{l}\text { Women who received immediate PPFP counseling from service providers at any time before } \\
\text { delivery. } 1=y e s, 0=\text { otherwise }\end{array}$ \\
\hline \multirow{2}{*}{$\begin{array}{l}\text { Delivery } \\
\text { mode }\end{array}$} & Women who delivered in the facilities either as normal or assisted delivery. \\
\hline & $\begin{array}{l}1=\text { normal delivery, } 0=\text { assisted delivery (delivered with vacuum support, delivered with forceps } \\
\text { support, delivered with surgical support) }\end{array}$ \\
\hline
\end{tabular}


Table 2. Socio-Demographic Characteristics of Postpartum Women

\begin{tabular}{|c|c|c|c|}
\hline Variables & $\mathrm{N}(\%)$ & $\begin{array}{l}\text { Used MWHs } \\
\mathrm{N}(\%)\end{array}$ & $\begin{array}{l}\text { Not used MWH } \\
\mathrm{N}(\%)\end{array}$ \\
\hline \multicolumn{4}{|l|}{ Age in year } \\
\hline$<25$ & $252(28.9)$ & $97(27)$ & $155(30)$ \\
\hline $25-30$ & $403(46.3)$ & $159(44)$ & $244(48)$ \\
\hline $31+$ & $216(24.8)$ & $103(29)$ & $113(22)$ \\
\hline Average age \pm SD & 27.7 years, \pm 5.6 & 28 years, \pm 5.9 & 27.7 years, \pm 5.6 \\
\hline \multicolumn{4}{|l|}{ Residence } \\
\hline Rural & 708 (81.2) & $324(92)$ & $384(74.2)$ \\
\hline Urban & 164(18.8) & $30(8)$ & $134(25.8)$ \\
\hline \multicolumn{4}{|c|}{ Attend formal school } \\
\hline Yes & $465(53.2)$ & $187(52)$ & $278(53)$ \\
\hline No & 419(47.4) & $174(48.9)$ & $245(46.8)$ \\
\hline \multicolumn{4}{|l|}{ Educational status } \\
\hline Primary (1-6) & $318(69.4)$ & $177(56)$ & $249(48)$ \\
\hline Secondary (7-10) & $104(22.7)$ & $144(46)$ & $174(33)$ \\
\hline Higher (11+) & $36(7.9)$ & $40(13)$ & $100(19)$ \\
\hline \multicolumn{4}{|l|}{ Marital status } \\
\hline Married & 706 (80.9) & $282(80)$ & $424(82)$ \\
\hline Live together & $136(15.6)$ & $57(16)$ & $79(15)$ \\
\hline Divorced/single & $31(3.5)$ & $15(4)$ & $16(3)$ \\
\hline
\end{tabular}


Table 3. Reproductive Histories of Postpartum Women

\begin{tabular}{|c|c|c|c|}
\hline Variables & $\mathrm{N}(\%)$ & $\begin{array}{l}\text { Used MWHs } \\
\mathrm{N}(\%)\end{array}$ & $\begin{array}{l}\text { Not Used MWH } \\
\mathrm{N}(\%)\end{array}$ \\
\hline Average number of births (live \& still) & $3.2, \pm 1.9 \mathrm{SD}$ & $3.4, \pm 2.02 \mathrm{SD}$ & $3.22, \pm 3 S D$ \\
\hline Average number of live births & $3, \pm 1.7 \mathrm{SD}$ & $3.13, \pm 1.8 \mathrm{SD}$ & $1.9, \pm 1.74 S D$ \\
\hline \multicolumn{4}{|l|}{ Birth space } \\
\hline$<24$ months & $91(13.6)$ & $34(13)$ & $57(14)$ \\
\hline 24 to 35 months & $225(33.5)$ & $88(33)$ & $137(34)$ \\
\hline$>35$ months & $355(52.9)$ & $148(55)$ & $207(52)$ \\
\hline \multicolumn{4}{|l|}{ Ever used FP } \\
\hline Yes & $742(84.1)$ & $297(82)$ & $445(85)$ \\
\hline No & $140(15.9)$ & $64(17.7)$ & $76(14.6)$ \\
\hline \multicolumn{4}{|l|}{ FP method ever used } \\
\hline DMPA & $411(55.5)$ & $166(56)$ & $245(55)$ \\
\hline Implanon & $269(36.3)$ & $115(38)$ & $154(35)$ \\
\hline Jadelle & $22(3)$ & $2(1)$ & $20(5)$ \\
\hline Others & $39(5.3)$ & $16(5)$ & $23(5)$ \\
\hline \multicolumn{4}{|l|}{ Number of ANC visits } \\
\hline $0-1$ & $17(1.9)$ & $6(2)$ & $11(2)$ \\
\hline $2-3$ & $258(29.9)$ & $109(31)$ & $146(29)$ \\
\hline $4+$ & $586(68.1)$ & $233(66)$ & $353(69)$ \\
\hline \multicolumn{4}{|l|}{ Facility visit experience for any services } \\
\hline Yes & $773(87.7)$ & $329(91)$ & $444(84.9)$ \\
\hline No & $108(12.3)$ & $32(8.8)$ & $76(14.6)$ \\
\hline \multicolumn{4}{|l|}{ Facility delivery experience } \\
\hline Yes & $633(71.9)$ & $250(69.3)$ & $383(73.2)$ \\
\hline No & $248(28.1$ & $110(30.6)$ & $138(26.5)$ \\
\hline \multicolumn{4}{|l|}{ Child immunization experience } \\
\hline Yes & $760(86.9)$ & $313(86.9)$ & $447(86.8)$ \\
\hline No & $115(13.1)$ & $47(13.1)$ & $68(13.2)$ \\
\hline
\end{tabular}




\begin{tabular}{|c|c|c|c|}
\hline \multirow[t]{2}{*}{ Characteristics } & \multicolumn{2}{|c|}{ Women Delivered in the HCs } & \multirow[t]{2}{*}{ p-values } \\
\hline & MWH Users (\%) & Walk-in/MWH Non-Users (\%) & \\
\hline \multicolumn{4}{|l|}{ Stay at MWHs (in days) } \\
\hline$>6$ & $196(54.7)$ & & \\
\hline $6-10$ & $76(21.2)$ & & \\
\hline $11-15$ & $31(8.7)$ & & \\
\hline $16+$ & $55(15.4)$ & & \\
\hline Average day & $8.24, \pm 8.8 \mathrm{SD}$ & & \\
\hline \multicolumn{4}{|c|}{ IPPFP counseling service received } \\
\hline Yes & $272(76)$ & $365(70)$ & 0.059 \\
\hline No & $86(24.02)$ & $155(29.8)$ & \\
\hline \multicolumn{4}{|c|}{ Adopted IPPFP (from counseled women) } \\
\hline \multicolumn{4}{|l|}{ Yes } \\
\hline \multirow[t]{2}{*}{ No } & $148(54)$ & $174(48)$ & 0.008 \\
\hline & $124(46)$ & $190(52)$ & \\
\hline \multicolumn{4}{|c|}{ Women who adopted IPPFP in the facility } \\
\hline \multicolumn{4}{|l|}{ Yes } \\
\hline \multirow[t]{2}{*}{ No } & $160(44) 198(55.3)$ & $187(36)$ & 0.007 \\
\hline & & $334(64.2)$ & \\
\hline \multicolumn{4}{|l|}{ Time to receive IPPFP } \\
\hline Within 10 minutes & $66(41.3)$ & $55(30.4)$ & 0.036 \\
\hline Within 48 hrs & $94(58.8)$ & $126(69.6)$ & \\
\hline \multicolumn{4}{|c|}{ PPFP Contraceptive methods } \\
\hline IUCD & $32(20.3)$ & $19(10.6)$ & 0.011 \\
\hline Implanon & $112(70.9)$ & $124(69.3)$ & 0.901 \\
\hline Jadelle & $9(5.7)$ & $27(15.1)$ & 0.009 \\
\hline Others & $5(3.2)$ & $9(5)$ & 0.217 \\
\hline \multicolumn{4}{|c|}{ Reasons for not using IPPFP } \\
\hline Want to be pregnant & $51(26.3)$ & $79(25)$ & \\
\hline \multicolumn{4}{|c|}{ No information about availability of the service } \\
\hline No counseling on PPFP & $26(13.4)$ & $44(13.9)$ & \\
\hline Fear of side effects & $29(14.9)$ & $52(16.5)$ & 0.017 \\
\hline No sexual contact & $24(12.4)$ & $24(7.6)$ & \\
\hline
\end{tabular}


Table 5. Bivariate and Multivariable Logistic Regression Result for Factors Associated with Immediate Postpartum Family Planning Use

\begin{tabular}{|c|c|c|c|c|}
\hline Variables & COR $(95 \% \mathrm{Cl}$ & $\begin{array}{l}\mathrm{p}- \\
\text { value }\end{array}$ & AOR $(95 \% \mathrm{Cl}$ & $\begin{array}{l}\mathrm{p}- \\
\text { value }\end{array}$ \\
\hline \multicolumn{5}{|l|}{ Age group in years } \\
\hline$<25$ & 1 & & & \multirow[b]{2}{*}{.452} \\
\hline & $\begin{array}{l}1.67(1.20- \\
2.33)\end{array}$ & \multicolumn{2}{|l|}{0.002} & \\
\hline$>30$ & $\begin{array}{l}1.64(1.12- \\
2.40)\end{array}$ & 0.011 & & .525 \\
\hline Residence (Urban/Rural) & $\begin{array}{l}1.53(1.06- \\
2.19)\end{array}$ & 0.023 & & .226 \\
\hline \multicolumn{5}{|l|}{ Educational level } \\
\hline Illiterate & 1 & & & \\
\hline Primary school (1-6 G) & $.94(.69-1.26)$ & 0.66 & & .979 \\
\hline Secondary school and above & $.53(.35-.81)$ & 0.003 & & $.022 *$ \\
\hline Marital status (Married/Other) & $\begin{array}{l}1.87(1.33- \\
2.64)\end{array}$ & 0.000 & $\begin{array}{l}2.04(1.37- \\
3.03)\end{array}$ & $.000 * *$ \\
\hline \multicolumn{5}{|l|}{ Number of living children } \\
\hline $1-2$ & 1 & & & \\
\hline $3-4$ & $\begin{array}{l}1.72(1.26- \\
2.34)\end{array}$ & 0.001 & & .125 \\
\hline 5 and above & $1.3(0.9-1.88)$ & 0.162 & & .851 \\
\hline Ever used FP (No/Yes) & $\begin{array}{l}1.48(1.01- \\
2.18)\end{array}$ & 0.046 & & .344 \\
\hline Number of ANC Visits <4/4+ & $1.25(.93-1.69)$ & .136 & & .255 \\
\hline Visited HF for Child immunization (No/Yes) & $\begin{array}{l}3.32(2.02- \\
5.44)\end{array}$ & 000 & $\begin{array}{l}3.17(1.72- \\
5.85)\end{array}$ & $.000 * \star$ \\
\hline Use MWHs (No/Yes) & $\begin{array}{l}1.46(1.11- \\
1.92)\end{array}$ & 0.007 & $\begin{array}{l}1.48(1.08- \\
2.04)\end{array}$ & $.016^{*}$ \\
\hline Have information on PPFP (No/Yes) & $\begin{array}{l}4.79(3.39- \\
6.79)\end{array}$ & 0.000 & $\begin{array}{l}1.97(1.28- \\
3.03)\end{array}$ & $.002^{\star *}$ \\
\hline \multicolumn{5}{|c|}{$\begin{array}{l}\text { Received IPPFP counseling before or during delivery } \\
\text { (No/Yes) }\end{array}$} \\
\hline & $\begin{array}{l}9.17(5.85- \\
14.38)\end{array}$ & 0.000 & $\begin{array}{l}5.26(3.12- \\
8.87)\end{array}$ & $.000 * \star$ \\
\hline
\end{tabular}

